\title{
Teaching Design and Exploration of Integrated Curriculum of Art in Middle and Primary Schools
}

\author{
Shengde Fang \\ Huanggang Normal University \\ Huanggang, Hubei, China 438000
}

\begin{abstract}
Integrative study is the most prominent highlight of China's basic educational reform, which sets integrated curriculum and adds integrative study field in the content of course, such as "comprehensive and exploratory" field in art subject. This paper discusses the coincident point of limit of how to look for material of integrated curriculum, masters the subjectivity limit of art subject, and realizes the proper transformation between the teacher and student in integrative study.
\end{abstract}

Keywords - integrative study; design of integrated curriculum; coincident limit

\section{RAISING OF THE PROBLEM: SETTING OF INTEGRATIVE STUDY AND INTEGRATED CURRICULUM}

Integrative study is the reform trend of course of basic education all over the world nowadays, also a new feature of modern education development. The educational theory of citizens' qualification and humanity-centered curriculum in US, UK and Germany, and Japan's "time for integrative study" are all concentrated reflection of such developing trend.

Three files, "The Decision on the Foundation Education Reform And Development of State Council", "Basic Education Curriculum Reform (trial implementation)", "Experimental Program of Curriculum Provision of Compulsory Education", stress the importance of integrative study, and require "primary schools to strengthen integrated curriculum, middle schools to combine branched curriculum with integrated curriculum", and "increase integrative practice activities in middle and primary schools". ("Decision") "Set integrated curriculum to fit the demand of different areas and students' demand, reflect the balance, integrity and selectivity of the curriculum structure", "Set integrative activity from primary school to high school and make it a required course". ("Outline"), especially the "Experimental Program of Curriculum Provision of Compulsory Education" stresses again that the principle of curriculum provision is to "strengthen the integrity of curriculum:

- pay attention to students' experience, strengthen penetration of subjects;

- set integrated curriculum, set curriculum of Morality

Fund project: Project of Edong education and culture research center, key research base of humanities and social sciences of colleges in Hubei: let Dongpo culture enter the art classes of primary and middle schools in Huangzhou 2014002803;

2015 key project of Hubei educational science plan: the route and method for Huangzhou Dongpo culture of entering art classes in stage of compulsory education. and Life for first and second grades, set curriculum of morality and society for third to sixth grades, set science class for third to ninth grades, and set art class for first to ninth grades;

- add integrative practice activity, whose content mainly includes education of information technology, investigative study, community service, social practice and education of labor and technology."

Based on this, further guide curriculum design in "curriculum standards of various subjects in compulsory education (draft)", apart from reflecting integrity in integrated curriculum, add integrative study field in the content of subject curriculum, such as "integrative study" in Chinese curriculum, "integration and practice in" in math curriculum, and "integration and exploration" in art curriculum and so on. After ten years of practice and exploration and eight years of modification and optimization, "curriculum standards of various subjects in compulsory education (2011)" came out, which stressed "pay special attention to examination of the ability of comprehensively adopting knowledge to analyze and solve problems and practice ability in detailed situation" in "actively promote reform of assessment and examination system" of the executing request. Under the guidance of the evaluation system and assessment criterion, "integrative study" becomes the most important education mode and a theme on which researchers focus in the stage of compulsory education.

\section{SEEK FOR LIMIT: ORGANIC INTEGRATION OF INTEGRATED CURRICULUM CONTENT OF ART}

The major curriculum content which reflects the integrative study of fine art in primary and middle schools mainly concentrates upon the study field of "integration and exploration". The setting of this field is aimed at make up the deficiency of branched curriculum from the aspect of interdiscipline, develop students' ability of integrative practice and exploration. It is divided into three layers: firstly it fuses all the learning areas of art, and integrates "shape \& expression", "design \& application" and "appreciation \& comment" according to the demand of the curriculum; secondly art integrates with other subjects such as Chinese music, math and ideology and morality; thirdly, art connects to realistic society, and knows the relation between art and nature, art and life, art and culture and art and technology to conduct investigative and integrative art activity. The 3 layers are crossed and overlapped in different degree. ${ }^{[1]}$ 
The "curriculum standards of various subjects in compulsory education (2011)" also points out that the teaching of field of "integration and exploration" needs teachers to change thinking set and look for the joint point among all types of art, between art and other subjects and art and realistic society, design abundant curriculum which highlights the feature of art subject, pay special attention to discussion and exploration centered on students, lead them to actively explore the method of combining art and other subjects, and art and social life, and develop interdisciplinary study activities. ${ }^{[2]}$

We can further deepen the joint point of interdiscipline into "coincident limit". For example, in the poem "Goose", the control training of lines in art can coincide with the visual description of "bending" and "toward", and the color training and coincide with colors in the sentence "Floating on green water by feathers in white, with red-webbed feet stirring in blue dye." If it shall fully express the situation of this poem, there shall be control training of line and shape, and also color training, so the degree of coincident limit of the subject language of art and Chinese will be higher than the former two.

Besides, in art education, it also needs to consider the coincident limit of difficulty degree of training and the students' accepting ability. In Appendix I, "reciting texts of excellent poems" of "Chinese curriculum standard in compulsory education (2011)", "Goose" is the fourth one, ${ }^{[3]}$ which is suitable for students of first and second grades to recite according to study progress. In the required curriculum content in "Art curriculum standard in compulsory education (2011)", students of first to second grades can "try to paint with line, shape and color." ${ }^{[4]}$ Comparing these two curriculum standards, the design of integrated curriculum of art and design in first to second grades can take "Goose" as creation theme. With the deepening of curriculum, the degree of coincident limit also grows.

Via above analysis and teaching practice of "coincident limit" of art integrated curriculum, students can not only improve the expressive ability of art by art training, but also further understand the realm of the poem and expressive method of words.

Similarly, we can also adopt the research principle of "coincident limit" to design the integrated curriculum of "art and life, culture". Seek for material that can enter art class from life and culture, such as visual image of daily vessel, figure, stationery, study and life situation, festival gift, festival activity and traditional culture. The key and difficult points of design of such integrated curriculum reflect in how to master the coincident limit of students' life experience, cultural cognition and art study.

Over a long period, our primary and secondary school students are under institutionalized, knowledge-based and scientific education system, and the double pressure from the school and family make lack life experience and cultural perception. Consequently, designing integrated curriculum of art and life and culture has to seek for the coincident limit among art material, technique expressing ability and life experience according to students' life experience and cultural perception step by step, and in this process it also needs to refer to study progress of other subjects and keep broadening the expressing range of curriculum.

\section{MASTERING THE LIMIT: IMPROVE THE DESIGN EFFECT OF CURRICULUM}

There is a mastering of extent in the development the anything, "going too far is as bad as not going far enough", "gilding the lily" and "longing for more" are all description of not mastering the extent. The coincident limit described above also has the problem of "extent", which can be understood as the "marginal utility" in the field of economics. Its theory involves complicated formula conversion, and the curriculum design discussed in this paper only needs to understand "diminishing marginal utility", which means the marginal utility of consumers continuously consuming certain product when the consumption quantity of other products are not changed within certain time, and it decreases when it reaches maximal utility value with the increase of consumption quantity, and even presents negative growth. For example, when people are extremely thirsty and need to drink, the first glass of water they drink is the most lightsome, but as their thirst reduces, their desire for the next glass of water keeps reducing, and it reaches the margin when they are not thirsty at all, at this time, if they go on drinking, they will feel uncomfortable, and the more they drink, the more uncomfortable they get, which is disutility.

There are always teachers worrying about "exceeding" in the design of art integrated curriculum. Just like the diminishing marginal utility, when the teaching hours are not changed, as knowledge of other subjects increases, the target performance of the integrative study also improves, but if they can't master the "extent" of increase of knowledge of other subjects, they will "devastate their own field". Domestic and overseas scholars conclude this issue and think that the integrated curriculum has advantage in cultivating students' ability of comprehensively solving the problem and improving initiative of study while owning some disadvantages, too. For example, the curriculum system is enough systematic; it's hard to integrate subjects and master the limit; it weakens traditional study ability and looks down upon knowledge, which makes students "ignorant" easily; during the execution of the integrated curriculum, it's easy to fall into the extreme trend of energism and experientialism if it's not mastered well. ${ }^{[5]}$ To avoid these disadvantages, researchers appeal from different angles to defend the bottom line of science while advocating the integrative study of various subjects, and such "voice" is most prominent in Chinese subject. In the field of art subject, it shall be based on the subject of art and never deviate from the noumenon of art curriculum.

So how to defend this bottom line, the author thinks that the key is the subjectivity and dominance of teachers. Firstly, the teachers shall take art curriculum standard and textbook as guidance outline when they design the integrated curriculum, make it clear that the teaching objective is centered on the objective of art students and supplemented by integrity, and integrity of other fields must develop around the objective of art study. Secondly, guarantee the dominant role of art study during teaching, if the students deviate from the objective of art study, the teacher shall remind and guide in time. Finally, 
in the stage of evaluation, further sort out the subjectivity and limit of integrative study of art curriculum.

However, the integrative study is put forward in the wave of changing views on curriculum, teaching and study, the text above has clarified the "elasticity" of curriculum design, and does it return to traditional teaching view to advocate the subjectivity of teachers while defending the noumenon of art curriculum? Will it limit the initiative and exploration of students? Thus, after dealing with the subject limit of art subject, it also needs to master another limit the limit of teacher and student.

Modern curriculum theory researchers generally think that education is a continuous process, a process of lifelong learning. In this process, education should face learners, and the student is the explorer and constructor of knowledge. In teaching practice, the subjectivity of students can not be clearly expressed in the process of education, but reflect the subjectivity of students via students who master the method in the teaching content arranged by the teachers, namely the relation between "teachers-content" and "students-method". Thanks to the complicated layers and diversified content of integrated curriculum of art, it can't generally stipulate that the design of integrated curriculum is centered on teachers-content or students-method but decide according to the content of detailed curriculum design. Taking 3 integrative layers in the field of "integrity and exploration" as examples, the curriculum design of integrity (first layer) of various fields of art and integrity (second layer) of art and other subjects pays more attention to dimensions of "knowledge and skill" and "process and method" in the teaching objective, and it shall center on teachers-content, and focus on the subjectivity and dominance of teachers during design and process of teaching. The integrity (third layer) of art and realistic society pays attention to the dimensions of "emotion, attitude and value" in teaching objective, which shall center on students-method and fully represent the subjectivity of students, and teachers no longer pass on pre-organized knowledge system to students as authority of knowledge, but students discuss and decide the content and detailed execution scheme of study in groups according to their own interest, hobby, demand and opinion under the guidance of teachers, and directly talk to the realistic society.

\section{CONCLUSION}

The integrative study used to be the major study mode in education in ancient schools, and the integrated curriculum also played a dominant role. For example, the teaching of learning to read of "One Thousand Character Primer" and "Three Character Classic" also contained teaching of ethics, astronomy, geography and history. With the development of natural science, knowledge is continuously divided and refined, which promotes the formation of branched education. The revival of modern integrative study is the result of long accumulation of history as well as the product of maturity of theory system.

The "integrity" of the integrated curriculum is mainly attributed to the fact that the integrative object which can act as curriculum content has factor and possibility of "coincident limit" but also has difference of degrees of coinciding. Designers of the integrated curriculum shall rationally analyze the relation between factors and factor and students' ability in "coincident limit", explore the diminishing marginal utility, master the proportion of art subject and other subjects, highlight the subjectivity of art subject, master the rational transformation between teacher subject and student subject in integrative study, strive to realize maximal marginal utility of the objective of integrative study.

\section{REFERENCES}

[1] Art curriculum standard in compulsory education [M]. Beijing: Beijing Normal University Press.2012.2:11.

[2] Art curriculum standard in compulsory education [M].Beijing: Beijing Normal University Press.2012.2:11.

[3] Chinese curriculum standard in compulsory education [M].Beijing: Beijing Normal University Press.2012.2:35.

[4] Art curriculum standard in compulsory education [M].Beijing: Beijing Normal University Press.2012.2:12.

[5] Xiong Mei. The new normal form of modern integrated curriculum: theory and practice of integrative study[M]. Beijing: Science and Education Press.2001: 77-78. 